\title{
Treatment of macular hole retinal detachment
}

\author{
Yoon-Kee Lai
}

\begin{abstract}
Seven patients with macular hole retinal detachment were treated by intravitreal gas injection with or without release of subretinal fluid. Macular buckling, diathermy, cryopexy, or vitrectomy were not used. The patients were placed prone for eight hours a day until the gas had absorbed. In five of the seven patients the retina became reattached within three days and remained reattached with follow-up periods of three to 22 months (average nine months). It is believed that such detachments are due to vitreoretinal traction and the intravitreal gas bubble relieves this traction. This technique is simple, safe, and does not require costly or sophisticated instruments. It has an added advantage in preserving macular function.
\end{abstract}

Many surgical techniques have been described for the treatment of retinal detachment due to macular holes. ${ }^{1-4}$ These include the use of macular plombs and posterior scleral resection, with the use of diathermy, cryopexy, or photocoagulation round the macular hole to create chorioretinal adhesions. However, these technically difficult procedures have high complication rates $^{5}$ and poor visual results because of the destruction of the macula.

In $1974 \mathrm{Scott}^{6}$ used intravitreal silicone oil injections to flatten out 32 cases successfully. The use of silicone oil was also advocated by others. ${ }^{7}$ Unfortunately silicone oil has definite short- and long-term complications which limits its use. $^{8}$

In 1982 Gonvers and Machemer ${ }^{9}$ showed that macular hole retinal detachments could be successfully treated by pars plana vitrectomy and gas tamponade without the need for inducing chorioretinal scarring, thereby preserving macular function. Another macula preserving method was introduced by Blankenship in 1984. ${ }^{10} \mathrm{He}$ exchanged liquid vitreous with an intravitreal gas bubble under indirect ophthalmoscopic control.

Recently Miyake ${ }^{11} 12$ has reported a simplified method of treating macular hole retinal detachment by intravitreal gas injection with or without external release of subretinal fluid. Vitrectomy was not required, nor was cryopexy or any other form of chorioretinal destruction performed. The results of this technique in seven patients are presented in this report.

Department of

Ophthalmology, Faculty of Medicine, University of Malaya, 59100 Kuala Lumpur, Malaysia Y-K Lai

Correspondence to: Dr Y-K Lai.

Accepted for publication 8 November 1989

\section{Patients and materials}

Between November 1987 and June 1989 seven patients with macular hole retinal detachments were treated in the University Hospital, Kuala Lumpur. The inclusion criterion was that the retinal detachment was due solely to a macular hole. Any patient with visible vitreoretinal traction or preretinal or subretinal fibrosis was excluded from the study. Patients with a macular hole together with any other retinal breaks were also excluded.

There were three male and four female patients. Their ages ranged from 45 to 65 years. All were myopic; of these six had refractive errors greater than 6 dioptres. Vitreous degeneration was present in all. No case was traumatic in nature. The time from onset to diagnosis ranged from one week to three months.

Macular hole retinal detachment can be classified according to the extent of the detachment: ${ }^{13}$

Type I detachment limited to the perimacular area.

Type II detachment extending to equator but not to ora.

Type III detachment extending to ora in at least one quadrant.

Type I detachments do not require treatment. The seven patients were classified into two treatment groups based on whether they were type II or type III detachments.

There were four patients with type III detachments. These were treated in the following manner. After induction of anaesthesia (either general or local) subretinal fluid was released at the equator in the most dependent quadrant. A mixture of $50 \%$ sulphur hexafluoride was injected with a $26 \mathrm{G}$ needle into the vitreous via the pars plana in phakic patients or the limbus in aphakic patients. The amount injected was sufficient to reform the eyeball firmly. This amount was $1.5 \mathrm{ml}$ or more in all cases. The central retinal artery circulation was checked by an indirect ophthalmoscope. The patient was then kept prone for at least eight hours a day until all the gas had been absorbed, usually between one and two weeks.

Patients with type II macular hole retinal detachments did not have release of subretinal fluid because of its posterior location. Instead an anterior chamber paracentesis was performed to soften the eye. Pure sulphur hexafluoride was then injected into the vitreous cavity in the same manner as in type III patients. The amount injected did not exceed $2.0 \mathrm{ml}$ in any patient. After injection of the gas these patients were treated in the same manner as type III patients.

\section{Results}

Five of the seven patients were successfully treated by this method. The retina became completely reattached within three days in all gas none of these patients suffered any recurrences during the follow-up period (three months to 22 months, average nine months). All five patients had improvement in their visual 
TABLE I Summary of clinical data

\begin{tabular}{|c|c|c|c|c|c|c|c|}
\hline Patient & 1 & 2 & 3 & 4 & 5 & 6 & 7 \\
\hline $\begin{array}{l}\text { Age (yrs) } \\
\text { Sex }\end{array}$ & $\begin{array}{l}64 \\
M\end{array}$ & $\begin{array}{l}45 \\
F\end{array}$ & $\begin{array}{l}65 \\
M\end{array}$ & $\begin{array}{l}57 \\
F\end{array}$ & $\begin{array}{l}60 \\
F\end{array}$ & $\begin{array}{l}55 \\
\mathrm{~F}\end{array}$ & $\begin{array}{l}53 \\
M\end{array}$ \\
\hline Refractive error & $-6 \cdot 0$ & $-20 \cdot 0$ & $-15 \cdot 0$ & -1.5 & $-18 \cdot 0$ & $-10 \cdot 0$ & $-7 \cdot 0$ \\
\hline $\begin{array}{l}\text { Detachment type } \\
\text { Duration of }\end{array}$ & II & III & III & III & II & III & II \\
\hline detachment (days) & 7 & 10 & 60 & 90 & 10 & 7 & 90 \\
\hline $\begin{array}{l}\text { Visual acuity: } \\
\text { preoperative } \\
\text { postoperative } \\
\text { Success }\end{array}$ & $\begin{array}{l}\text { HM } \\
\text { CF } \\
\text { No }\end{array}$ & $\begin{array}{l}\text { HM } \\
1 / 60 \\
\text { No }\end{array}$ & $\begin{array}{l}\text { HM } \\
\text { CF } \\
\text { Yes }\end{array}$ & $\begin{array}{l}\text { HM } \\
2 / 60 \\
\text { Yes }\end{array}$ & $\begin{array}{l}1 / 60 \\
6 / 60 \\
\text { Yes }\end{array}$ & $\begin{array}{l}\text { HM } \\
3 / 60 \\
\text { Yes }\end{array}$ & $\begin{array}{l}\text { CF } \\
6 / 60 \\
\text { Yes }\end{array}$ \\
\hline $\begin{array}{l}\text { Follow-up period } \\
\text { (months) }\end{array}$ & 22 & 16 & 10 & 5 & 4 & 3 & 3 \\
\hline
\end{tabular}

$\mathrm{HM}=$ hand movements. $\mathrm{CF}=$ counting fingers.

acuity (Table I). The fundal appearance of one month after surgery is shown in Fig 1.

Two of the patients had failure of treatment. Patient 1 had an aphakic type II detachment. He was treated as described and showed a partial response. The treatment was repeated twice but the detachment persisted. He then had a pars plana vitrectomy and gas tamponade procedure done. This was successful in reattaching his retina, with improvement in vision.

Patient 2 had a phakic type III detachment. She underwent the treatment as described. The retina was not completely attached after two weeks. However, she was reluctant to have the same procedure repeated. Instead she was successfully treated with a pars plana vitrectomy and gas tamponade, with improvement in vision.

In both these cases the presence of persistent posterior vitreoretinal adhesions was detected during vitrectomy. This was inferred by the tugging of the posterior retina during aspiration and cutting with the vitrectomy instrument round the area of the macular hole.

\section{Discussion}

Macular hole retinal detachment is believed to be due to vitreoretinal traction on the macula. After detachment has occurred the posterior vitreous face may be totally detached with no further traction, or there may be only a partial posterior vitreous detachment with persistent microscopic vitreoretinal adhesions. Such adhesions are often difficult to visualise, even with high magnification on slit-lamp biomicroscopy. However, their presence is often noted during vitrectomy, and the success of such an operation in relieving it further strengthens the case for such a cause.

The intravitreal gas possibly acts in two ways. (1) A bubble of sufficient size can rupture weak residual microscopic vitreoretinal adhesions, thereby relieving further traction. ${ }^{14}$ (2) It seals the macular hole while the subretinal fluid is being absorbed.

In the case of patients 1 and 2 it would appear that the gas bubble was unsuccessful in breaking all the residual microscopic vitreoretinal adhesions.

This method of treating macular hole retinal detachment is simple, safe, and effective. The operative technique is straightforward and takes approximately 15 minutes to perform. It can be done under local anaesthesia. Operative equip-



Figure 1: One month after surgery.

ment needed is minimal. The safety of the procedure has been noted in this and in Miyake's ${ }^{12}$ series. There had been no operative complications and up to the present time; no occurrence of proliferative vitreoretinopathy has been documented. In this study it was also noted that failure of the technique did not worsen the prognosis when a pars plana vitrectomy had to be performed. A high success rate of $83 \%$ was obtained by Miyake using this technique. In the present series a lower but still highly satisfactory success rate of $71 \%$ was obtained.

Though the exclusion criteria would appear to restrict the number of cases that can be treated in this manner, in practice many of the patients can be selected for treatment. During the duration of this series eight patients with macular hole retinal detachments were seen. Of these only one had to be excluded, because of the presence of early proliferative vitreoretinopathy. Miyake was able to select 18 out of 24 patients with macular hole retinal detachments who were suitable for this method of treatment. It is likely that the proliferative potential in this condition is low, given that some patients have not been treated for at least three months without any evidence of retinal fibrosis.

1 Margherio RR, Schepens CL. Macular breaks: management. Am 7 Ophthalmol 1972; 74: 233-40.

2 Meyer-Schwickerath G. Indications and limitations of light coagulation of the retina. Ophthalmology 1959; 63: 725-38. 3 Leaver PK, Cleary PE. Macular hole and retinal detachment. Trans Ophthalmol Soc UK 1975; 95: 145-7.

4 Siam AL. Management of central retinal detachment due to macular hole. Brf Ophthalmol 1979; 57: 351-4.

5 Aaberg TM. Macular holes. A review. Surv Ophthalmol 1970 15: $139-45$

6 Scott JD. Macular holes and retinal detachment. Trans Ophthalmol Soc UK 1974; 94: 319-24.

7 Cockerham W, Schepens CL, Freeman HM. Silicone injections in retinal detachment. Mod Probl Ophthalmol 1969; 8: 525-40.

8 Leaver PK, Grey RHB, Garner A. Silicone oil injection in the treatment of massive preretinal retraction. II. Late compli-
cations in 93 eyes. Br $\mathcal{Y}$ Ophthalmol $1979 ; 63: 361-7$.

9 Gonvers M, Machemer R. A new approach to treating retinal detachment with macular hole. Am $\mathcal{F}$ Ophthalmol 1982; 94: 468-72.

10 Blankenship G. Liquid vitreous-intravitral gas exchange treatment of myopic macular holes and detachments. Basic and advanced vitreous surgery course, Rome, September, 1984.

11 Miyake Y. A simplified method of treating retinal detachment with macular hole. Am F Ophthalmol 1984; 97: 243-5.

12 Miyake Y. A simplified method of treating retinal detachment with macular hole. Long term follow up. Arch Ophthalmol 1986; 104: 1234-6.

13 Margherio RR, Schepens CL. Macular breaks. I. Diagnosis, etiology and observations. Am $\mathcal{F}$ Ophthalmol 1972; 74: 219-32.

14 Blodi CF. Folk JC. Treatment of macular hole retinal detachments with intravitreal gas. Am F Ophthalmol 1984; 98: 811 . 